\title{
Dissolution Method Development and Validation for Lercanidipine Hydrochloride Tablets
}

Farhatjahan Shaikh*, Vandana Patel, Meenakshi Patel, Naazneen Surti

Babaria Institute of Pharmacy, BITS Edu Campus, Varnama, Vadodara, Gujarat, India

\section{ABSTRACT}

e-mail: fari1145@gmail.com

Lercanidipine hydrochloride $(\mathrm{HCl})$ is L-type calcium channel blocker widely used in the management of hypertension. According to the BCS classification system, it is classified under BCS class II drugs, showing low solubility and high permeability. The dissolution profile and thus the in vivo performance of this class of drugs widely depend on their solubility and hence their behaviour in dissolution medium. Lercanidipine $\mathrm{HCl}$ is not official in any pharmacopeia, so no official dissolution method is available. The present work is mainly focussed on development and validation of a dissolution test that can be used as a quality control test for lercanidipine $\mathrm{HCl}$ tablets and formulations. Saturation solubility and sink conditions that can be achieved in different media suggested that $0.1 \mathrm{~N} \mathrm{HCl}$, acetate buffer $\mathrm{pH} 4.5$, and phosphate buffer $\mathrm{pH} 6.8$ can be used as a dissolution medium. Dissolution tests of lercanidipine $\mathrm{HCl}$ tablets were carried out in these different media at different rotation speeds using a USP type II (paddle) apparatus. The most suitable dissolution conditions were $0.1 \mathrm{~N} \mathrm{HCl} \mathrm{pH} 1.2\left(900 \mathrm{~mL}\right.$ at $\left.37 \pm 0.5^{\circ} \mathrm{C}\right)$ as a dissolution medium and a paddle apparatus at $100 \mathrm{rpm}$ for $60 \mathrm{~min}$. The analysis of released lercanidipine $\mathrm{HCl}$ was done by ultraviolet spectrophotometry. The developed method was validated according to $\mathrm{ICH}$ guidelines. This method showed linearity with an $r^{2}$ value of 0.999 within the concentration range of $2-20 \mu \mathrm{g} / \mathrm{mL}$. The method was found to be accurate with recoveries ranging from $98.50 \%$ to $103.72 \%$. The interday and intraday precision was below RSD $2 \%$. The developed method can effectively be used for quality control evaluation of lercanidipine $\mathrm{HCl}$ tablets.

KEYWORDS: Lercanidipine $\mathrm{HCl}$, dissolution, sink conditions, validation

\section{INTRODUCTION}

D issolution testing is considered as an important tool to evaluate the performance of oral solid dosage forms, and more stress is given to dissolution testing by pharmaceutical industries and regulatory authorities (1-6). Dissolution tests can detect variation in lot-to-lot quality of a drug product during formulation stages and after changes in the manufacturing process $(2,3)$. It is one of the important quality control tests used to assure product uniformity and batch-to-batch bioequivalence (7). It is very challenging to develop an in vitro dissolution test for drugs with limited solubility $(8,9)$. The discriminating power of a dissolution method can be demonstrated by analysing the dissolution profiles under deliberate changes made in the method (10). Once the product development stage is over, dissolution is an important test to monitor regular quality of commercial batches of drug formulation, which is the focus of all regulatory agencies worldwide $(11,12)$. Developed dissolution methods are validated in terms of specificity, accuracy, precision, and robustness, to make sure that they are suitable for their intended use $(13,14)$.
Lercanidipine $\mathrm{HCl}$ is a new third generation calcium channel blocker belonging to the 1,4-dihydropyridine class. It blocks entry of calcium into L-type calcium channels of smooth muscles resulting in peripheral vasodilatation and reduction in blood pressure (15). Chemically it is 2[(3,3-diphenylpropyl) (methyl) amino]-1, 1-dimethylethyl methyl 2,6-dimethyl-4-(3-nitrophenyl)-1, 4-dihydropyridine-3, 5- dicarboxylate hydrochloride (16). As per BCS classification, lercanidipine $\mathrm{HCl}$ is a BCS class II drug that is freely soluble in methanol and practically insoluble in water, having a pKa value of $6.83(17,18)$. Commercially, it is available in tablet dosage forms in strengths of 10 and $20 \mathrm{mg}$. Lercanidipine $\mathrm{HCl}$ is not official in any pharmacopeia and currently no quality control or discriminatory dissolution method is available for raw material and tablets (19).

The purpose of this study is to develop and validate a method of dissolution testing that can be used for routine quality control of lercanidipine $\mathrm{HCl}$ tablets (and other dosage forms). 


\section{MATERIALS AND METHODS}

\section{Reagents}

Lercanidipine $\mathrm{HCl}$ was received as a gift sample from Alembic Research Centre, Vadodara, Gujarat, India. Lotensy ${ }^{\circledR} 10$ tablets (Batch No. HSR2259, Sun Pharmaceutical Industries Ltd.) containing $10 \mathrm{mg}$ of lercanidipine were purchased from local market. All chemicals and solvent used were of analytical grade. Potassium dihydrogen phosphate (S D Fine-Chem Limited, India), sodium hydroxide, sodium acetate (Qualigens, India), glacial acetic acid, hydrochloric acid (S D Fine-Chem Limited, India) were used for preparation of different buffer solutions. Double distilled water was used for all the analysis purpose. Phosphate buffer (pH 6.8), acetate buffer ( $\mathrm{pH} 4.5$ ), and $0.1 \mathrm{~N} \mathrm{HCl}$ were prepared as per USP 27.

\section{Apparatus}

The dissolution method was developed using the Tablet Dissolution Tester Model (TDT-08L, Electrolab, Mumbai, India). Ultraviolet (UV) measurements of all samples were done using a UV spectrophotometer (UV-1800 PC, Shimadzu, Japan).

\section{Solubility determination}

Solubility of lercanidipine $\mathrm{HCl}$ was determined in three different media: $0.1 \mathrm{M} \mathrm{HCl}$, acetate buffer $\mathrm{pH} 4.5$, and Phosphate buffer $\mathrm{pH}$ 6.8. Excess amount of lercanidipine $\mathrm{HCl}$ was added into conical flasks containing $25 \mathrm{~mL}$ of

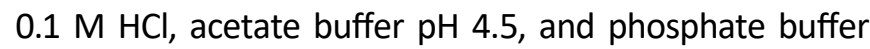
$\mathrm{pH} 6.8$ maintained at $37 \pm 0.5{ }^{\circ} \mathrm{C}$. The samples were subjected to sonication for $10 \mathrm{~min}$, and closed conical flasks were agitated for $24 \mathrm{~h}$ at $37 \pm 0.5{ }^{\circ} \mathrm{C}$ in an orbital shaker. After achieving equilibrium, samples were filtered through Whatman grade 41 filters (Sigma-Aldrich) and concentration of lercanidipine $\mathrm{HCl}$ was measured at 236 $\mathrm{nm}$. All measurements were done in replicates $(n=6)$.

\section{Optimization of Dissolution Test}

The dissolution test was developed and validated using a multistation ( $n=6)$ USP dissolution apparatus by Electrolab. The effects of different $\mathrm{pH}$ of dissolution medium and different rotation speed were evaluated. All tests were performed at $37 \pm 0.5{ }^{\circ} \mathrm{C}$ with $900 \mathrm{~mL}$ of dissolution medium. Sample aliquots were collected at 10, 20, 30, 40, 50 , and 60 minutes, a few millilitres of dissolution medium were discarded and filtered, and drug release was assayed using a validated UV spectrophotometric method. The standard solution used for the dissolution tests was prepared with lercanidipine equivalent to $10 \mathrm{mg}$.

\section{Validation of Dissolution Test}

The developed in vitro dissolution method was validated using recent guidelines (20-22). To demonstrate reproducibility and reliability, the method was evaluated for specificity, linearity, accuracy, precision, and robustness.

\section{Specificity}

Evaluation of specificity was done using placebo samples consisting of all the excipients without active substance. The placebo samples were introduced in dissolution vessels $(n=3)$ containing $900 \mathrm{~mL}$ of dissolution medium maintained at $37 \pm 0.5^{\circ} \mathrm{C}$. The vessels were stirred at 75 rpm for 1 hour using a paddle (USP apparatus 2). Aliquots were collected and analysed.

\section{Linearity}

Aliquots of lercanidipine $\mathrm{HCl}$ stock solution $(100 \mu \mathrm{g} / \mathrm{mL})$ were diluted with phosphate buffer $\mathrm{pH} 6.8$, acetate buffer $\mathrm{pH} 4.5$, and $0.1 \mathrm{~N} \mathrm{HCl}$ to obtain concentration of 2-20 $\mu \mathrm{g} / \mathrm{mL}$. Solutions were prepared in triplicate, and linearity was calculated by least-square linear regression analysis.

\section{Accuracy and precision}

To evaluate accuracy of the dissolution method, recovery of known amounts of lercanidipine $\mathrm{HCl}$ reference standard added to placebo was calculated. Stock solution of $1 \mathrm{mg} / \mathrm{mL}$ was prepared in methanol. From the stock solution, aliquots of $4.5,9$, and $13.5 \mathrm{~mL}$ were added to make $900 \mathrm{~mL}$ of dissolution medium in a dissolution vessel kept at $37 \pm 0.5^{\circ} \mathrm{C}$ (final concentration of 5,10 , and $15 \mu \mathrm{g} / \mathrm{mL}$ ). The dissolution medium was stirred at 150 rpm for 60 minutes. A $10-\mathrm{mL}$ of aliquot was withdrawn, filtered, and analysed at $236 \mathrm{~nm}$. The experiment was repeated on three different days, and recovery of the added drug substance $(n=9)$ was determined.

The same solutions used in accuracy studies were used to establish intraday and interday precision, which were calculated based on \%RSD data of the results.

\section{Robustness}

To access robustness of the method, parameters like analyst, equipment, and laboratory were changed. The dissolution test of Lotensy $^{\circledR} 10$ was carried out in $900 \mathrm{~mL}$ of $0.1 \mathrm{~N} \mathrm{HCl}$ maintained at $37 \pm 0.5^{\circ} \mathrm{C}$ in a USP type 2 apparatus at $100 \mathrm{rpm}$ with two different instruments, with two different analysts, in two different laboratories. The dissolution data obtained were compared with the initial data. 


\section{Stability studies}

Stability of the solutions was evaluated in comparison with the standard solutions. Sample solutions were kept on a shaker at $37 \pm 0.5^{\circ} \mathrm{C}$ for 1 hour, then kept at room temperature for 24 hours. Aliquots of sample solutions were evaluated in triplicate at 0,1 , and $24 \mathrm{~h}$ using freshly prepared standard solution.

\section{Evaluation of release kinetics}

Release kinetics of the drug release from tablets were studied using four mathematical models named zero order, first order, Higuchi, and Hixson-Crowell. Details of the mathematical models are as follows.

Zero-order model: $Q_{\mathrm{t}}=Q_{0}+K_{0} \mathrm{t}$;

First-order model: $\log Q_{\mathrm{t}}=\log Q_{0}+\left(K_{1} \mathrm{t}\right) / 2.303$;

Higuchi model: $f_{\mathrm{t}}=K_{\mathrm{H}} \mathrm{t}^{1 / 2}$;

Hixson-Crowell model: $W_{0}^{1 / 3}-W \mathrm{t}^{1 / 3}=K_{\mathrm{s}} \mathrm{t}$;

where

$Q_{\mathrm{t}}=$ amount of drug dissolved in time t;

$Q_{0}=$ initial amount of drug in the solution;

$K_{0}$ and $K_{1}=$ zero and first order release constants,

respectively;

$f t=$ amount of drug released in time $t$ by surface unity;

$K_{\mathrm{H}}=$ Higuchi dissolution constant;

$W_{0}=$ initial amount of drug in the pharmaceutical dosage

form;

$W_{\mathrm{t}}=$ remaining amount of drug in the pharmaceutical

dosage form at time $t$;

$K_{\mathrm{s}}=$ a constant incorporating the surface-volume relation.

\section{RESULTS AND DISCUSSION}

\section{Solubility}

Lercanidipine $\mathrm{HCl}$ showed $\mathrm{pH}$-dependent solubility, with the highest solubility achieved in $0.1 \mathrm{~N} \mathrm{HCl}$ (Table 1). This can be explained by the pKa value of lercanidipine $\mathrm{HCl}$, which is 6.83 , leading to complete ionisation of the drug molecule at a low $\mathrm{pH}$ of $0.1 \mathrm{~N} \mathrm{HCl}(\mathrm{pH} 1.2)$. As the $\mathrm{pH}$ of the medium is increased, the solubility of lercanidipine $\mathrm{HCl}$ markedly decreased from $82.35 \mu \mathrm{g} / \mathrm{mL}$ in $0.1 \mathrm{~N} \mathrm{HCl}$ to $49.43 \mu \mathrm{g} / \mathrm{mL}$ in acetate buffer $\mathrm{pH} 4.5$ and finally reaching as low as $9.85 \mu \mathrm{g} / \mathrm{mL}$ in phosphate buffer $\mathrm{pH}$ 7.0. Above $\mathrm{pH} 6$, solubility remains nearly constant. These solubility data form the basis for selection of dissolution media and sink conditions.
Table 1. Saturation Solubility of Lercanidipine $\mathrm{HCl}$ and Sink Conditions in Different Dissolution Media $(n=3)$.

\begin{tabular}{|l|c|c|c|}
\hline \multicolumn{1}{|c|}{ Medium } & $\begin{array}{c}\text { Average } \\
\text { Absorbance }\end{array}$ & $\begin{array}{c}\text { Solubility } \\
(\mu \mathrm{g} / \mathrm{mL}), \\
\text { mean } \pm \text { SD }\end{array}$ & $\mathrm{C}_{\mathrm{s}} / \mathrm{C}_{\mathrm{d}}$ \\
\hline $0.1 \mathrm{~N} \mathrm{HCl}, \mathrm{pH} \mathrm{1.2}$ & 0.257 & $82.35 \pm 1.06$ & 7.41 \\
\hline Acetate buffer, $\mathrm{pH} \mathrm{4}$ & 0.157 & $51 \pm 0.82$ & 4.59 \\
\hline Acetate buffer, $\mathrm{pH} 4.5$ & 0.152 & $49.43 \pm 0.51$ & 4.44 \\
\hline Acetate buffer, pH 5 & 0.110 & $36.41 \pm 0.51$ & 3.27 \\
\hline Phosphate buffer, pH 6.2 & 0.037 & $13.56 \pm 0.13$ & 1.22 \\
\hline Phosphate buffer, pH 6.8 & 0.026 & $10.30 \pm 0.06$ & 0.927 \\
\hline Phosphate buffer, pH 7.0 & 0.025 & $9.85 \pm 0.14$ & 0.88 \\
\hline
\end{tabular}

$C_{s}$, saturation solubility of lercanidipine $\mathrm{HCl}$ in $900 \mathrm{~mL}$ dissolution medium; $C_{d}$, dose of lercanidipine $\mathrm{HCl}$ in tablet formulation.

\section{Dissolution Test Optimization}

For development of the dissolution method, the objective was set to achieve a dissolution profile showing $<50 \%$ drug release in 15 minutes and $>85 \%$ drug release in 30 min for an immediate release dosage form of lercanidipine $\mathrm{HCl}$. Solubility of lercanidipine $\mathrm{HCl}$ demonstrated significant change over $\mathrm{pH} 1.2-6.8$, which suggests that dissolution of lercanidipine $\mathrm{HCl}$ is dependent on the $\mathrm{pH}$ of the medium.

For a formulation not official in monograph, it is recommended that the dissolution profile should be compared in three different compositions of media within the $\mathrm{pH}$ range of 1-7.5 (23). The effect of $\mathrm{pH}$ on the dissolution of lercanidipine $\mathrm{HCl}$ tablets was studied in $0.1 \mathrm{~N} \mathrm{HCl}$, acetate buffer $\mathrm{pH} 4.5$, and phosphate buffer pH 6.8 using a USP type 2 apparatus at $50 \mathrm{rpm}$, as shown in Figure $1 \mathrm{~A}$, which covers high, mid, and low solubility regions.

The dissolution process of disintegrating tablets can be best expressed by paddle apparatus, as it has inherent advantages over a rotating basket apparatus (24). Hence, all dissolution tests of lercanidipine $\mathrm{HCl}$ tablets (disintegrating tablets) were performed with a paddletype apparatus. To study the effect of rotation speed of paddle, dissolution profiles were generated at 50,75 , and $100 \mathrm{rpm}(3)$.

Percent drug release of lercanidipine $\mathrm{HCl}$ in different $\mathrm{pH}$ dissolution mediums supports the saturation solubility results, wherein the dissolution is incomplete and very slow at $\mathrm{pH} 6.8$. At lower $\mathrm{pH} 4.5$, fast and nearly complete drug release is obtained; however, in $0.1 \mathrm{~N} \mathrm{HCl}$, lercanidipine $\mathrm{HCl}$ has a gradual ascending and plateaushaped dissolution curve, which confirms the distinct dissolution profile. 

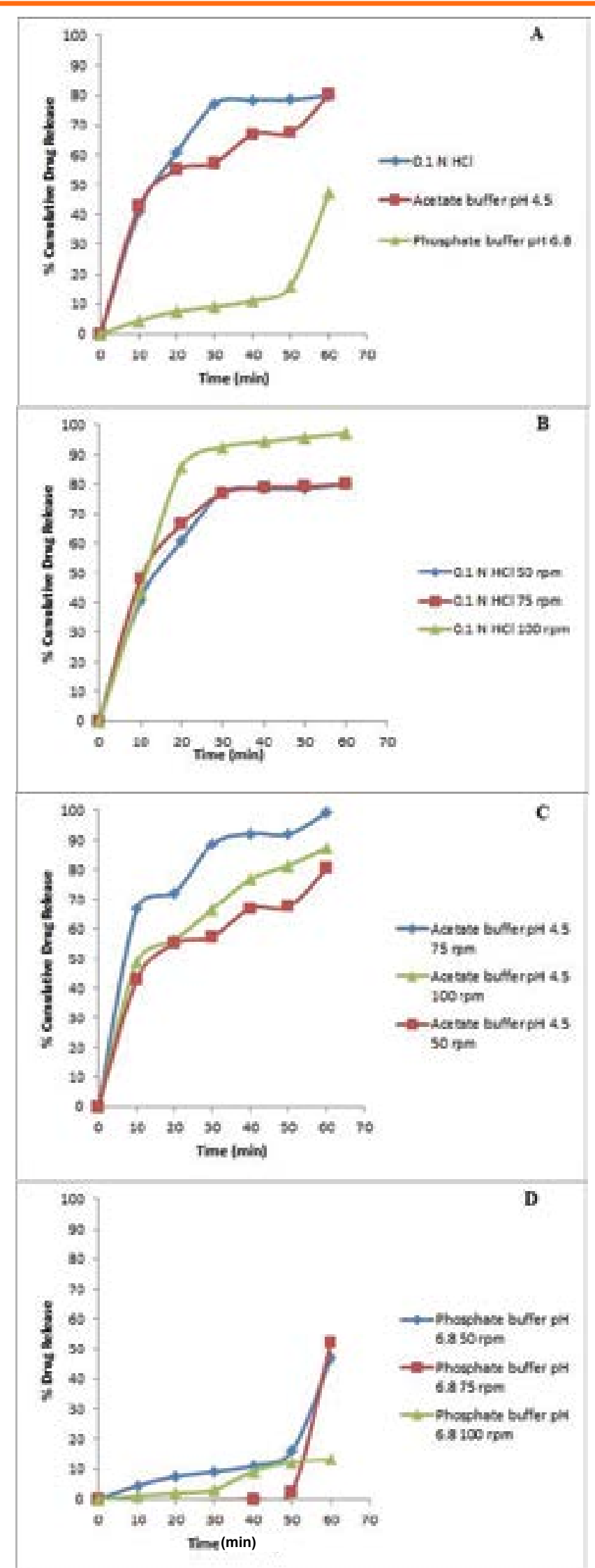

Figure 1. Dissolution profiles of lercanidipine $\mathrm{HCl}$ tablets using paddle apparatus in (A) $900 \mathrm{~mL} 0.1 \mathrm{~N} \mathrm{HCl}$, acetate buffer $\mathrm{pH}$ 4.5, and phosphate buffer 6.8 at $50 \mathrm{rpm}$; (B) $0.1 \mathrm{~N} \mathrm{HCl}$ at 50, 75, and $100 \mathrm{rpm}$; (C) acetate buffer pH 4.5 at 50, 75, and $100 \mathrm{rpm}$; and (D) phosphate buffer pH 6.8 at 50, 75 and $100 \mathrm{rpm}$.
Lercanidipine $\mathrm{HCl}$ exhibits very low saturation solubility in phosphate buffer $\mathrm{pH} 6.8$ and, in turn, has a low $\mathrm{C}_{\mathrm{s}} / \mathrm{C}_{\mathrm{d}}$ ratio (where $\mathrm{C}_{s}$ is saturation solubility of lercanidipine $\mathrm{HCl}$ in 900 $\mathrm{mL}$ dissolution medium; $\mathrm{C}_{\mathrm{d}}$ is $10 \mathrm{mg}$ of lercanidipine $\mathrm{HCl}$ in tablet formulation) (Table 1). As discussed by Ashokraj et al (25), low $C_{s} / C_{d}$ ratio results in non-sink conditions, which leads to a slow rate of dissolution due to limited solubility of lercanidipine $\mathrm{HCl}$ in phosphate buffer $\mathrm{pH}$ 6.8. The nonsink condition of phosphate buffer $\mathrm{pH} 6.8$ is supported by drug release obtained at different rotation speeds in Figure 1D.

The drug release profile of lercanidipine $\mathrm{HCl}$ in acetate buffer $\mathrm{pH} 4.5$ at the stirring speeds of 50 and $100 \mathrm{rpm}$ showed less than $85 \%$ release in 30 minutes (Figure 1C). These results do not satisfy the minimum criteria for dissolution methods set by the U.S. Food and Drug Administration (3). At $75 \mathrm{rpm}$, the criteria are satisfied, but reproducible dissolution data are not obtained. Therefore, use of acetate buffer $\mathrm{pH} 4.5$ as a dissolution medium is not advisable to develop a dissolution method that can be used for routine quality control testing.

The dissolution profile obtained with $0.1 \mathrm{~N} \mathrm{HCl}$ at 50,75 , and $100 \mathrm{rpm}$ is shown in Figure 1B. Table 1 depicts that a three-times greater sink condition for the dose level of $20 \mathrm{mg}$ lercanidipine $\mathrm{HCl}$ is maintained only with 0.1 $\mathrm{N} \mathrm{HCl}$, suggesting that the same media can be used across all dose levels for a given product. From the dissolution profiles, it is evident that, when $0.1 \mathrm{~N} \mathrm{HCl}$ was employed as dissolution medium, slow and complete release of lercanidipine $\mathrm{HCl}$ was observed. At different rotation speeds of the paddle apparatus, lercanidipine $\mathrm{HCl}$ had a distinct dissolution profile with gradual increase and then constant plateau, and less than $50 \%$ release in $15 \mathrm{~min}$; however, at 50 and $75 \mathrm{rpm}$, the release obtained at $30 \mathrm{~min}$ was $77 \%$ and $76 \%$, respectively, which does not meet the objective of more than $85 \%$ release at $30 \mathrm{~min}$. Also, release of lercanidipine $\mathrm{HCl}$ in $20 \mathrm{~min}$ at $75 \mathrm{rpm}$ is lower than that obtained at $50 \mathrm{rpm}$, which can be explained by various factors such as inconsistent agitation of the dosage form, poor hydrodynamics achieved at this speed, tablet weight, hardness, etc. The dissolution profile obtained with $0.1 \mathrm{~N}$ $\mathrm{HCl}$ at $100 \mathrm{rpm}$ shows less than $50 \%$ drug release in 15 minutes and $>85 \%$ drug release in $30 \mathrm{~min}$. The dissolution release pattern of lercanidipine $\mathrm{HCl}$ suggests that the extent of release reaches a plateau at about $80 \%$ with a 50 and 75-rpm agitation speed, whereas at $100 \mathrm{rpm}$, nearly complete dissolution of lercanidipine $\mathrm{HCl}$ is achieved. 
From the experiments conducted and results obtained, a dissolution medium of $900 \mathrm{~mL}$ of $0.1 \mathrm{~N} \mathrm{HCl}$ at $37^{\circ} \mathrm{C}$ and a paddle apparatus at $100 \mathrm{rpm}$ was considered the optimum dissolution condition for lercanidipine $\mathrm{HCl}$ release.

\section{Validation of Dissolution Method}

After selecting the optimum dissolution test conditions, the dissolution method was validated $(26,27)$.

\section{Specificity}

The UV spectrophotometric method is used for the analysis because lercanidipine $\mathrm{HCl}$ has a chromophore group (28). Specificity of the method was evaluated by scanning the placebo samples with all the excipients without lercanidipine $\mathrm{HCl}$. The UV absorption scan of lercanidipine $\mathrm{HCl}$ showed a peak at $236 \mathrm{~nm}$, which was not obtained with placebo samples, and thus, no interference due to excipients used in the formulation was observed (Fig. 2A).

\section{Linearity}

The analytical method using $236 \mathrm{~nm}$ with UV spectrophotometry was found to be linear in the concentration range of $2-20 \mu \mathrm{g} / \mathrm{mL}$, with a slope of 0.0261 and $Y$ intercept -0.0171 . The correlation co-efficient was 0.999. The result of regression analysis confirms that the relationship between concentration and response is linear (Fig. 2B). As recommended, the concentration range evaluated for the dissolution test includes $\pm 20 \%$, covering both lowest expected and highest expected concentrations.

\section{Accuracy and precision}

Accuracy of a method was assessed by performing recovery of a known amount of drug reference standard added to the placebo. As recommended, recoveries ranging from $95 \%$ to $105 \%$ are acceptable for dissolution tests (4). The percentage of drug recovered for the dissolution method was found between $98.50 \%$ and $103.72 \%$, which lies within the range and shows that the dissolution method is accurate (Table 2). To evaluate intraday precision, three different concentration levels were analysed at different time intervals during a day. For intermediate precision, same solutions were analysed at different days.

The results of precision study are depicted in Table 2, which confirms that the dissolution method shows good precision with RSD lower than $2 \%$.
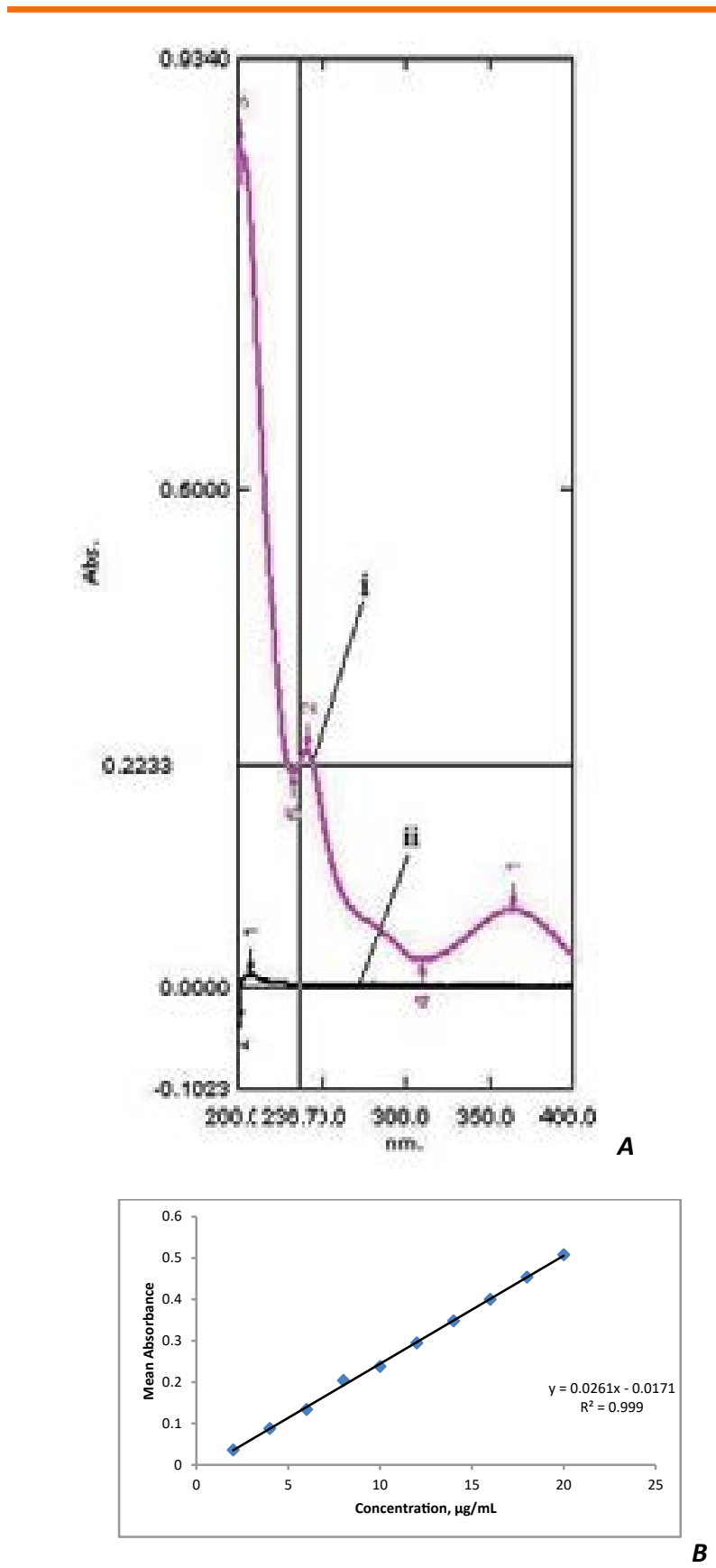

Figure 2. Ultraviolet spectrophotometry results for lercanidipine $\mathrm{HCl}$ in dissolution medium (0.1 N HCl): (A) lercanidipine $\mathrm{HCl}$ (i) and placebo (ii); (B) calibration curve of lercanidipine $\mathrm{HCl}$ at $236 \mathrm{~nm}$. 
Table 2. Dissolution Test Accuracy and Precision Results for Lercanidipine $\mathrm{HCl}(n=3)$.

\begin{tabular}{|c|c|c|}
\hline $\begin{array}{c}\text { Concentration } \\
\text { added }(\mu \mathrm{g} / \mathrm{mL})\end{array}$ & $\begin{array}{c}\text { Concentration found } \\
(\mathrm{ug} / \mathrm{mL}), \text { mean } \pm \text { SD }\end{array}$ & $\begin{array}{c}\text { Recovery } \\
(\%)\end{array}$ \\
\hline 5 & $5.07 \pm 0.07$ & $99.69-103.52$ \\
\hline 10 & $9.99 \pm 0.17$ & $98.50-102.33$ \\
\hline 15 & $15.15 \pm 0.29$ & $99.13-103.72$ \\
\hline \multicolumn{3}{|c|}{ Intraday Precision } \\
\hline 5 & $5.11 \pm 0.09$ & 102.20 \\
\hline 10 & $9.88 \pm 0.15$ & 98.80 \\
\hline 15 & $15.15 \pm 0.28$ & 101 \\
\hline \multicolumn{3}{|c|}{ Intermediate precision } \\
\hline 5 & $4.98 \pm 0.03$ & 99.60 \\
\hline 10 & $9.92 \pm 0.09$ & 99.20 \\
\hline 15 & $14.99 \pm 0.12$ & 99.93 \\
\hline
\end{tabular}

\section{Robustness}

To study the robustness of method, the analytical method was evaluated in different situations such as changing an analyst, changing an instrument, and changing a laboratory. No such change altered the response of the method beyond the permissible limit of RSD 5\% (Table 3). These results indicate that the method can withstand small and deliberate changes, illustrating robustness of method employed.

\section{Stability Studies}

The stability of lercanidipine $\mathrm{HCl}$ in different dissolution media was estimated by analysing reference and standard solutions at room temperature for $24 \mathrm{~h}$. The study was performed to demonstrate stability of solutions over the entire period of dissolution profile determination and for an extended time. The result of stability studies demonstrates that the solution of lercanidipine $\mathrm{HCl}$ is stable in the $\mathrm{pH}$ conditions studied for dissolution method development, with results ranging from $90.96 \%$ to $99.04 \%$ (Table 4).

\section{CONCLUSION}

Dissolution testing is one of the important analytical tools used to evaluate the effect of any change that takes place in a drug product formulation or process. The dissolution test can also be effectively used to predict the in vivo behaviour of a drug product if proper in vitro/in vivo correlation is established. Using the dissolution profile obtained with different conditions, it was possible to

Table 3. Robustness of Dissolution Test with Change in Analyst, Equipment, and Laboratory $(n=3)$.

\begin{tabular}{|c|c|c|c|c|c|c|c|}
\hline \multirow{2}{*}{$\begin{array}{c}\text { Sample } \\
\text { No. }\end{array}$} & \multirow{2}{*}{$\begin{array}{l}\text { Time } \\
(\min )\end{array}$} & \multicolumn{6}{|c|}{ Average \% Release \pm SD } \\
\hline & & $\begin{array}{c}\text { Analyst } \\
1 \\
\end{array}$ & $\begin{array}{c}\text { Analyst } \\
\text { II }\end{array}$ & $\begin{array}{c}\text { Instrument } \\
\text { I }\end{array}$ & $\begin{array}{c}\text { Instrument } \\
\text { II }\end{array}$ & $\begin{array}{c}\text { Laboratory } \\
\text { I }\end{array}$ & $\begin{array}{c}\text { Laboratory } \\
\text { II }\end{array}$ \\
\hline 1 & 0 & 0 & 0 & 0 & 0 & 0 & 0 \\
\hline 2 & 10 & $43.04 \pm 0.25$ & $43.29 \pm 0.81$ & $42.94 \pm 0.39$ & $43.39 \pm 0.70$ & $42.74 \pm 0.31$ & $43.59 \pm 0.54$ \\
\hline 3 & 20 & $85.69 \pm 0.94$ & $86.64 \pm 0.74$ & $85.91 \pm 1.25$ & $86.42 \pm 0.43$ & $86.57 \pm 1.19$ & $85.75 \pm 0.51$ \\
\hline 4 & 30 & $94.73 \pm 0.86$ & $91.96 \pm 0.81$ & $93.84 \pm 0.86$ & $92.85 \pm 2.00$ & $94.05 \pm 1.19$ & $92.64 \pm 1.72$ \\
\hline 5 & 40 & $95.61 \pm 1.20$ & $93.69 \pm 0.73$ & $95.19 \pm 1.21$ & $94.11 \pm 1.30$ & $94.90 \pm 0.82$ & $94.40 \pm 1.73$ \\
\hline 6 & 50 & $96.96 \pm 0.79$ & $95.47 \pm 0.85$ & $96.84 \pm 0.80$ & $95.59 \pm 1.01$ & $96.55 \pm 0.44$ & $95.88 \pm 1.42$ \\
\hline 7 & 60 & $98.58 \pm 0.63$ & $97.00 \pm 1.35$ & $98.48 \pm 0.59$ & $97.10 \pm 1.48$ & $98.45 \pm 0.55$ & $97.13 \pm 1.52$ \\
\hline \multicolumn{2}{|c|}{ Average at $60 \mathrm{~min}$} & \multicolumn{2}{|c|}{$97.79 \pm 0.79$} & \multicolumn{2}{|c|}{$97.79 \pm 0.69$} & \multicolumn{2}{|c|}{$97.79 \pm 0.66$} \\
\hline \multicolumn{2}{|c|}{$\%$ RSD at $60 \mathrm{~min}$} & \multicolumn{2}{|c|}{0.80} & \multicolumn{2}{|c|}{0.69} & \multicolumn{2}{|c|}{0.67} \\
\hline
\end{tabular}

Table 4. Stability Data for Lercanidipine $\mathrm{HCl}(n=3)$.

\begin{tabular}{|c|c|c|c|c|}
\hline & \multicolumn{2}{|c|}{ Concentration (ug/mL) } & & \\
\hline Medium & $\mathbf{0 ~ h}$ & $\mathbf{2 4} \mathrm{h}$ & $\mathbf{w} / \mathrm{w}(\%)$ & Difference from 0 $\mathrm{h}(\%)$ \\
\hline $0.1 \mathrm{~N} \mathrm{HCl}, \mathrm{pH} 1.2$ & 82.35 & 81.56 & 99.04 & 0.96 \\
\hline Acetate buffer, pH 4 & 51.00 & 48.36 & 94.80 & 5.18 \\
\hline Acetate buffer, pH 4.5 & 49.43 & 48.63 & 98.38 & 1.63 \\
\hline Acetate buffer, pH 5 & 36.41 & 34.86 & 95.74 & 4.28 \\
\hline Phosphate buffer, pH 6.2 & 13.56 & 12.65 & 93.28 & 6.73 \\
\hline Phosphate buffer, pH 6.8 & 10.30 & 10.15 & 98.54 & 1.48 \\
\hline Phosphate buffer, pH 7 & 9.85 & 8.96 & 90.96 & 9.07 \\
\hline
\end{tabular}


establish dissolution test method for lercanidipine $\mathrm{HCl}$ tablets.

Dissolution testing performed with $900 \mathrm{~mL}$ of $0.1 \mathrm{~N} \mathrm{HCl}$ at $37 \pm 0.5^{\circ} \mathrm{C}$ and 100 -rpm speed in USP type II apparatus provides satisfactory results for lercanidipine $\mathrm{HCl}$ tablets.

Validation of dissolution method was carried out as per ICH guidelines, and method was found to be specific, linear, accurate, precise, and robust. The validated method can be effectively utilized for the routine assessment of the release profile of lercanidipine $\mathrm{HCl}$ from its formulations.

\section{ACKNOWLEDGEMENT}

The authors are thankful to Alembic Pharmaceuticals (Vadodara, Gujarat) for providing Lercanidipine $\mathrm{HCl}$ as a gift sample.

\section{CONFLICT OF INTEREST}

No conflict of interest has been declared by authors.

\section{REFERENCES}

1. Dressman, J. B.; Amidon, G. L.; Reppas, C.; Shah, V. P. Dissolution testing as a prognostic tool for oral drug absorption: immediate release dosage forms. Pharm. Res. 1998, 15 (1), 11-22. DOI: 10.1023/A:1011984216775.

2. Vaucher, L. C. Development and validation of a dissolution test for telithromycin in coated tablets. Quim. Nova 2009, 32 (5), 1-5. DOI: 10.1590/S0100-40422009000500041.

3. Dissolution Testing of Immediate Release Solid Oral Dosage Forms; Guidance for Industry; U.S. Department of Health and Human Services, Food and Drug Administration, Center for Drug Evaluation and Research (CDER), U.S. Government Printing Office: Washington, DC, 1997.

4. Immediate Release Solid Oral Dosage Forms, Scale-up and Postapproval Changes: Chemistry, Manufacturing and Controls, In Vitro Dissolution Testing, and In Vivo Bioequivalence Documentation; Guidance for Industry; U.S. Department of Health and Human Services, Food and Drug Administration, Center for Drug Evaluation and Research (CDER), U.S. Government Printing Office: Washington, DC, 1997.

5. SUPAC-MR: Modified Release Solid Oral Dosage Forms, Scaleup and Postapproval Changes: Chemistry, Manufacturing and Controls, In Vitro Dissolution Testing, and In Vivo Bioequivalence Documentation; Guidance for Industry; U.S. Department of Health and Human Services, Food and Drug Administration, Center for Drug Evaluation and Research (CDER), U.S. Government Printing Office: Washington, DC, 1997.

6. Extended Release Solid Oral Dosage Forms: Development, Evaluation and Application of In Vitro/In Vivo Correlations; Guidance for Industry; U.S. Department of Health and Human Services, Food and Drug Administration, Center for Drug Evaluation and Research (CDER), U.S. Government Printing
Office: Washington, DC, 1997.

7. Skelly, J. P. Bioavailability and bioequivalence. J. Clin. Pharmacol. 1976, 16, 539-543. DOI: 10.1177/009127007601601013.

8. Lobenberg, R.; Kramer, J.; Shah, V. P.; Amidon, G.L.; Dressman, J.B. Dissolution testing as a prognostic tool for oral drug absorption: dissolution behaviour of glibenclamide. Pharm. Res. 2000, 17 (4), 439-444. DOI: 10.1023/A:1007529020774.

9. Soni, T.; Nagda, C.; Gandhi, T.; Chotai, N. P. Development of discriminating method for dissolution of aceclofenac marketed formulations. Dissolution Technol. 2008, 15 (2), 31-35. DOI: 10.14227/DT150208P31

10. He, Z.; Zhong, D.; Chen, X.; Liu, X.; Tang, X.; Zhao, L. Development of a dissolution medium for nimodipine tablets based on bioavailability evaluation. Eu. J. Pharm. Sci. 2004, 21, 487-491. DOI: 10.1016/j.ejps.2003.11.009.

11. Anand, O.; Yu, L. X.; Conner, D. P.; Davit, B. M. Dissolution testing for generic drugs: an FDA perspective. AAPSJ. 2011, 13 (3), 328335. DOI: 10.1208/s12248-011-9272-y.

12. Darling, D. Regulatory expectations of presentation of dissolution data. Presented at the 3rd APS International PharmSci Conference, Nottingham, UK, Sept 12-14, 2012.

13. Galia, E.; Nicolaides, E.; Horter, D.; Lobenberg, R.; Reppas, C; Dressman, J.B. Evaluation of various dissolution media for predicting in vivo performance of class I and II drugs. Pharm. Res., 1998, 15 (5), 698-705. DOI: 10.1023/A:1011910801212.

14. Validation of analytical procedures: text and methodology Q2 (R1). International Conference on Harmonisation (ICH) Harmonized Triplicate Guideline. http://www.ich.org/ fileadmin/Public_Web_Site/ICH_Products/Guidelines/ Quality/Q2_R1/Step4/Q2_R1__Guideline.pdf. Published 2005. Accessed August 18, 2017.

15. Bang, L. M.; Chapman, T. M.; Goa, K. L. Lercanidipine: a review of its efficacy in the management of hypertension. Drugs. 2003, 63 (22), 2449-2472.

16. Shaikh, F.l.; Patel V. B. Enhancement of dissolution of lercanidipine hydrochloride using solid dispersion technique. Res. J. Rec. Sci. 2015, 4, 299-307.

17. Chung, Y. S.; Park, R. S.; Kim, S.; Juhn, J. H.; Kim, D. K.; Kim, Y. R.; Park, H. D.; Park, S. J.; Lee, S. H.; Kim, J. H.; Jung, M. Y. Complex formulation comprising Lercanidipine hydrochloride and valsartan and method for the preparation thereof. European Patent Application E2648730 A2, October 16, 2013. European Patent Office website. https://data.epo.org/gpi/EP2648730A2COMPLEX-FORMULATION-COMPRISING-LERCANIDIPINEHYDROCHLORIDE-AND-VALSARTAN-AND-METHOD-FOR-THEPREPARATION-THEREOF.

18. Kallakunta, V.R.; Bandari, S.; Jukanti, R.; Veerareddy, P. R. Oral self emulsifying powder of lercanidipine hydrochloride: formulation and evaluation. Powder Technol. 2012, 221, 375382. DOI: 10.1016/j.powtec.2012.01.032.

19. Dissolutions Methods. U.S. Department of Health and Human Services, Food and Drug Administration website. http:// 
www.accessdata.fda.gov/scripts/cder/dissolution/index.cfm. Accessed Dec 15, 2016.

20. The Use of Mechanical Calibration of Dissolution Apparatus 1 and 2-Current Good Manufacturing Practice (CGMP); Guidance for Industry; U.S. Department of Health and Human Services, Food and Drug Administration, Center for Drug Evaluation and Research (CDER), U.S. Government Printing Office: Washington, DC, 2010.

21. Breier, A. R.; Paim, C. S.; Steppe, M.; Schapoval, E. E. S. Development and validation of dissolution tests for fexofenadine hydrochloride capsules and coated tablets. J. Pharm. Pharm. Sci. 2005, 8 (2), 289-298.

22. Shohin, I. E.; Kulinich, J. I.; Ramensakya, G. V.; Vasilenko, G. F. Evaluation of in vitro equivalence for drugs containing BCS class II compound ketoprofen. Dissolution Technol. 2011, 18 (1), 2629. DOI: 10.14227/DT180111P26.

23. Gite, S.; Chogale, M.; Patravale, V. Development and validation of a discriminating dissolution method for atorvastatin delayedrelease nanoparticles using a flow-through cell: a comparative study using USP apparatus 4 and 1. Dissolution Technol. 2016, 23 (2), 14-20. DOI: 10.14227/DT230216P14.

24. Seeger, N.; Lange, S.; Klein, S. Impact of vibration and agitation speed on dissolution of USP prednisone tablets RS and various IR tablet formulations. AAPS PharmSciTech. 2015, 16 (4), 759-766. DOI: 10.1208/s12249-015-0356-3.

25. Ashokraj, Y.; Daroi, A.; Gupta, R.; Khanolkar, A.; Kulkarni, A.; Laud, S.; Pokale, M.; Shedge, S.; Date, P. Discriminatory dissolution method development and validation of etoricoxib tablets. Dissolution Technol. 2014, 21 (2), 30-35. DOI: 10.14227/ DT230216P30.

26. Kulkarni, A. P.; Shahnawaz, M.; Zaheer, Z.; Dehghan, M. H. G. Development and validation of a dissolution method for pioglitazone tablets. Dissolution Technol. 2012, 19 (4), 36-45. DOI: 10.14227/DT190412P36.

27. Donato, E. M.; Martins, L. A.; Froehlich, P. E.; Bergold, A. M. Development and validation of dissolution test for lopinavir, a poorly water-soluble drug, in soft gel capsules, based on in vivo data. J. Pharm. Biomed. Anal. 2008, 47, 547-552. DOI: 10.1016/j. jpba.2008.02.014.

28. Fortunato, D. Dissolution method development for immediate release solid oral dosage forms. Dissolution. Technol. 2005, 12 (3), 12-14. DOI: 10.14227/DT120305P12. 